optimum size for a public health department to have an infectious diseases epidemiological section, whose medical staff can devote some time and effort to the management of chronic enteric carriers. There is no doubt in my mind that a close liaison with carriers is very desirable for all concerned. This should of course be primarily the responsibility of the medical officer of health rather than the individual family doctors. The relationship should begin in hospital with all enteric cases, whether they subsequently become carriers or not. The emotional support given to potential carriers in the early months after discharge from hospital can be invaluable in establishing the relationship even in the more acutely disturbed cases where the family doctor may also be involved. In a larger study of enteric carriers in Western Germany, Rasch (1964) also concluded that more attention should be given to the medical and social welfare of carriers. Every carrier in group II is readily approachable at any time. In group I there are some who are either relatively unapproachable or who still resent their having been "neglected," with sporadic visits only from a sanitary inspector, with whom they were often reluctant to discuss personal problems related to their carrier state.

\section{Summary}

The personal, social, and environmental problems of the 18 chronic enteric carriers in the City of Edinburgh are described and discussed. A comparison is made of the acquired psychological disturbances of two numerically equal groups of carriers, discovered before and after an outbreak of paratyphoid $B$ in 1.963 , in relation to their public-health management.
Brief details are given of social, epidemiological, and clinical histories and personality types of the individual carriers.

Only two carriers had not been upset at all, while one at least had acquired a decided "leper complex." Some concern is felt about the younger carriers who are unmarried women and have a greater remaining life expectancy, particularly the youngest, aged 19, who was infected soon after leaving school and has already had her life considerably disturbed.

A close liaison between the public health department and individual carriers appears to have no effect in minimizing the occurrence of psychological disturbances, but there is no doubt in my mind of the desirability of such liaison for all concerned.

My thanks are due to Dr. J. L. Gilloran, medical officer of health, City of Edinburgh, for permission to publish this paper; to Dr. J. M. Mair, who provided me with the original stimulus; and to the University of Edinburgh Bacteriology Deparment and Miss L. M. Souness for their valuable assistance.

\section{REFERENCES}

Brit. med. F., 1963, 1, 1175.

$$
1964,2,1211 .
$$

Christie, A. B. (1964). Brit. med. f., 1, 1609.

Leff, S. (1957). Recent Outbreaks of Infectious Diseases. Lewis, London. Rasch, H. (1964). Z. ärztl. Fortbild. (Fena), 58, 335.

Sharp, J. C. M., Brown, P. P., and Sangster, G. (1964). Brit. med. f., 1, 1282.

Statutory Instrument (1959). No. 413. The Food Hygiene (Scotland) Regulations, 1959. H.M.S.O., London.

Woodward, T. E., Smadel, J. E., Ley, H. L., Green, R., and Mankikar, D. S. (1948). Ann. intern. Med., 29, 131.

\title{
Ampicillin for Persistent Typhoid Excreters, including a Clinical Trial in Convalescence
}

\author{
ELIZABETH M. RUSSELL,* M.B., CH.B., D.R.C.o.G. ; AUDREY SUTHERLAND,* M.B., CH.B., D.P.H., D.R.C.o.G. \\ WILLIAM WALKER,* M.A., M.B., F.R.C.P.ED., M.R.C.P.
}

Brit. med. F., 1966, 2, 555-557

One of the most serious consequences of typhoid fever is the carrier state. Approximately $30 \%$ of patients may still excrete Salmonella typhi immediately after completing treatment, but almost $90 \%$ of those become negative within one month (Vogelsang and $\mathrm{B} \varnothing \mathrm{e}, 1948)$. Anderson and Richards (1948) found that all nine convalescent excreters out of 110 cases cleared spontaneously. However, usually about $3 \%$ of patients contracting typhoid fever become chronic carriers-that is, they are found to be excreting Salm. typhi continuously or intermittently after a period of from six to twelve months following recovery from the acute stage of the illness.

When typhoid fever occurred in Aberdeen in 1964 (Walker, 1965) it was decided to follow the suggestion of Christie (1964) and test the efficacy of ampicillin in preventing the carrier state. With a possible total of 500 or more cases of typhoid, about 160 temporary and 16 chronic carriers might be expected. It was therefore decided to conduct a double-blind trial of ampicillin in early convalescent excreters by means of a strictly random allocation of identical ampicillin and inert capsules. It was not thought that there would be sufficient patients for testing more than one drug or one duration of treatment. In view of the wide publicity which attended this outbreak and

* From the City Hospital, Aberdeen. the treatment of the patients, it was considered necessary to explain fully to the patients the conduct of and reason for the trial and to invite them to participate. It was also agreed to carry out a sequential analysis of the results, so that if ampicillin were clearly of value the trial would be stopped and all excreters treated with it. In the event; sequential analysis gave no clear result.

\section{Conduct of Trial}

The trial was timed as early in convalescence as was feasible, since most patients were feeling well and were anxious to return home. The agreed criteria for discharge from hospital were three negative specimens of both stool and urine at four-day intervals beginning four days after the end of the initial treatment. It was therefore decided that any positive specimen occurring during this period would make the patient eligible to enter the trial provided that certain additional criteria were fulfilled. These were: (1) no known penicillin sensitivity, (2) no other antibiotic therapy at that time, and (3) the consent of the patient after having the double-blind nature of the trial, and its purpose, fully explained.

The dosage of ampicillin was $1 \mathrm{~g}$. six-hourly for adults, $0.75 \mathrm{~g}$. six-hourly for children aged 6-12 years, and $0.50 \mathrm{~g}$. 
six-hourly for children under 6 years. Both ampicillin and identical but inert capsules were given for 10 days, a longer course of treatment not being feasible because of possible lack of cooperation. Patients entering the trial were allocated to one of the two groups by a strictly random method. The key to the allocation was held by us, two of whom (E. M. R. and A. S.) constituted the medical staff of the Typhoid Co-ordinating Centre, and to these the physicians ${ }^{1}$ in clinical charge of patients could apply in case of need.

There were three agreed reasons for withdrawal from the trial: (1) sensitivity reaction to ampicillin, (2) clinical relapse of typhoid fever, and (3) the administration of another antibiotic for any reason. "Success" was judged to be the absence of the organism in all specimens of stool and urine taken after the trial had been completed. Three paired specimens (stool and urine each time) were taken at four-day intervals in hospital, starting four days after "treatment" ceased ; if these were all negative the patient was discharged from hospital and a minimum of another three paired specimens were collected at weekly intervals at home. For domestic food-handlers six negative weekly specimens were required, and for professional food-handlers nine. Three further sets of specimens from all patients were to be tested at $3,6,12$, and 24 months after discharge, the faeces specimen to be taken after a saline purge was given. "Failure" was judged to be the reappearance of the organism in any one specimen after the trial treatment period.

\section{Analysis of Trial}

Of 114 patients who entered the trial 23 were withdrawn, one because of penicillin sensitivity and 22 because of clinical relapse. A further six patients relapsed immediately on completing the trial. The results were therefore assessed on 85 patients, as is shown in Table I. In the ampicillin-treated group the success rate was $78 \%$, in the control group $55 \%$. There were fewer "failures" (all faecal excreters) who had ampicillin, the difference being of borderline significance $\left(x^{2}=3.99\right.$. $\left.\quad \mathrm{P}<0.050\right)$. Since it might be argued that the six

TaBle I.-Results of Clinical Trial of Ampicillin, Assessed on 85 Convalescent Excreters

\begin{tabular}{|c|c|c|c|c|c|c|c|}
\hline \multicolumn{5}{|c|}{ Treatment } & \multirow{2}{*}{$\begin{array}{l}\text { Success } \\
35(30) \\
22(27) \\
\end{array}$} & \multirow{2}{*}{$\begin{array}{l}\text { Failure } \\
10(15) \\
18(13) \\
\end{array}$} & \multirow{2}{*}{$\begin{array}{c}\text { Totals } \\
45 \\
40 \\
\end{array}$} \\
\hline $\begin{array}{l}\text { Ampicillin } \\
\text { Control }\end{array}$ & $\therefore$ & $\because$ & $\because$. & $\therefore$ & & & \\
\hline Both treatm & ents & .. & . & $\cdots$ & 57 & 28 & 85 \\
\hline
\end{tabular}

$x^{2}=3.99 ;$ d.f. $=1 ; P<0.05$, possibly significant. Expected figures are shown in parentheses.

TABLE II.-Results of Clinical Trial of Ampicillin, Assessed on 85 Convalescent Excreters, Plus Six Patients Who Relapsed After
Completing the Trial

\begin{tabular}{|c|c|c|c|c|c|c|c|}
\hline \multicolumn{5}{|c|}{ Treatment } & \multirow{2}{*}{$\begin{array}{l}\text { Success } \\
35(29) \\
22(28)\end{array}$} & \multirow{2}{*}{$\begin{array}{l}\text { Failure } \\
11(17) \\
23(17)\end{array}$} & \multirow{2}{*}{$\begin{array}{c}\text { Totals } \\
46 \\
45\end{array}$} \\
\hline $\begin{array}{l}\text { Ampicillin } \\
\text { Control }\end{array}$ & $\therefore$ & $\therefore$ & $\because$. & $\because$. & & & \\
\hline Both treatm & ients & $\ldots$ & .. & .. & 57 & 34 & 91 \\
\hline
\end{tabular}

patients who relapsed after completing the trial were failures, the assessment was repeated with them included (Table II). The success rate was thus $76 \%$ in the ampicillin group compared with $49 \%$ in the control. This result was of possible significance in favour of ampicillin $\left(\chi^{2}=6.06, P<0.0250\right)$. However, the patients who relapsed had not reached the end of the acute illness when they participated in the trial, and therefore were not true convalescent excreters, if convalescence is considered to begin only after the end of the complete illness and not merely after the initial illness. The occurrence of

${ }^{1}$ These were: Drs. L. S. Bain, D. Bell, N. S. Clark, W. H. Galloway, W. R. Gauld, D. T. Kay, A. Lyall, C. D. Needham, D. S. Short, J. M. Stowers, and W. Walker. bacteriaemia and toxic states in the patients who relapsed indicated a degree of infection too different from that in convalescent excreters to permit comparison.

The age distribution of the 85 patients in the trial, shown in Table III, was not significantly different from that of other convalescent excreters. The two trial groups, successes and failures together, were compared by age, sex, severity of the initial infection, and daily dosage of ampicillin on a weight basis, but no differences were found. The effect of different treatments for the acute illness on patients in the trial was also considered. Three hundred and ninety patients had been given a course of chloramphenicol and the remainder had been treated with ampicillin or a mixture of drugs, usually ampicillin and chloramphenicol. This meant that some patients in this minority treatment group who received ampicillin in the trial were in fact having a second course of it. However, there was no significant difference between the two trial groups in numbers of patients who had received chloramphenicol, ampicillin, or other initial treatment, nor did these different treatments have any significant effect on the results of the trial when the two groups were assessed separately.

TABle III.-Proportionate Age Distribution of Clinical-trial Patients Compared with All Typhoid Fever Patients and All Convalescent Excreters

\begin{tabular}{|c|c|c|c|}
\hline \multirow{2}{*}{$\begin{array}{c}\text { Age Group } \\
\text { (years) }\end{array}$} & \multicolumn{3}{|c|}{ Number of } \\
\hline & $\begin{array}{c}\text { Typhoid Fever } \\
\text { Patients }\end{array}$ & $\begin{array}{l}\text { Convalescent } \\
\text { Excreters }\end{array}$ & $\begin{array}{c}\text { Clinical Trial } \\
\text { Patients }\end{array}$ \\
\hline $\begin{array}{l}0-14 \\
15-29 \\
30-44 \\
45-59 \\
60 \text { and over }\end{array}$ & $\begin{array}{l}108(0 \cdot 2) \\
126(0 \cdot 3) \\
75(0 \cdot 15) \\
86(0 \cdot 2) \\
74(0 \cdot 15)\end{array}$ & $\begin{array}{ll}50(0 \cdot 3) \\
41(0 \cdot 3) \\
25(0 \cdot 15) \\
25(0 \cdot 15) \\
18(0 \cdot 1) \\
\end{array}$ & $\begin{array}{l}37(0.45) \\
19(0.2) \\
10(0.1) \\
15(0.2) \\
4(0.05) \\
\end{array}$ \\
\hline All ages & $469(1.0)$ & $159(1.0)$ & $85(1 \cdot 0)$ \\
\hline
\end{tabular}

Figures in parentheses indicate fraction of the total.

\section{Comment}

A clinical trial of ampicillin in 85 convalescent excreters did not clearly establish the value of ampicillin in reducing the incidence of temporary carriers. The success rate on ampicillin was $78 \%$, compared with $55 \%$ in the control group. However, the result was, if anything, favourable despite the fact that the timing of the trial, with the dosage and duration of treatment chosen, was not ideal, as is illustrated by the number of patients who relapsed during or after participation. In these cases the positive isolation which rendered the patient eligible for the trial occurred during the acute stage of the illness and not, strictly, in convalescence. This points the need for a further controlled trial of ampicillin a few weeks later in convalescence, with varying dosages and durations of treatment.

\section{Further Treatment of Convalescent Excreters}

\section{Prolonged Treatment with Ampicillin}

By the middle of July 1964-that is, two months after the beginning of the outbreak-more than half the convalescent excreters had cleared bacteriologically, either spontaneously or on treatment. There were still, however, some patients excreting Salm. typhi who were being detained in hospital for this reason. The final assessment of the trial of ampicillin had not yet been made, but the majority of clinicians believed it to be of value ; although a second trial was scientifically desirable, it might have been unethical and was in the circumstances certainly impracticable. All these patients and any giving positive specimens after discharge from hospital, unless they were known to be allergic to penicillin, were started on a threemonth course of ampicillin in a dosage of $1 \mathrm{~g}$. eight-hourly for adults and $0.75 \mathrm{~g}$. eight-hourly for children. This rendered the excreta of almost all patients negative, and they were dis- 
charged from hospital under the accepted clearance regimen for discharge of three paired negative specimens of faeces and urine at four-day intervals. Weekly specimens of faeces and urine were collected from all these patients while they were on ampicillin, and "clearance" for them after the end of treatment was as for the other patients-that is, three, six, or nine paired negative specimens at weekly intervals and each following a saline purge.

Of the 469 confirmed cases $78(16.6 \%)$ continued to excrete Salm. typhi in faeces for more than a month after the end of the acute illness, a figure comparable to that found by Garbat (1922). Of these 7810 were not given "long-term" ampicillin - five because of a known sensitivity to penicillin and five because they were very reluctant to be treated and were given a further chance to clear spontaneously, which they did. A further 16 patients did not complete the course of treatment10 because of sensitivity reactions, 3 because of diarrhoea, and 3 because of apathy. All 16 remained negative thereafter.

Of the 52 patients who completed the three-month course of ampicillin three became chronic faecal carriers. In addition, two penicillin-sensitive patients continued to excrete organisms. This relatively low incidence $(1 \%)$ of chronic carriers may have been a feature of the particular strain of Salm. typhi which caused this outbreak, as it was of the same strain at Oswestry (Jones, 1951). However, the incidence of convalescent excreters at an interval of a month after the end of the acute illness was much the same as is usually observed. It is possible that the treatment of convalescent excreters with ampicillin, whether for 10 days or for three months, did have an effect in reducing the incidence of chronic carriers.

\section{Treatment of Six Temporary Carriers}

Two patients who excreted Salm. typhi immediately after three months on ampicillin were given a further six weeks' treatment in a dosage of $1 \mathrm{~g}$. eight-hourly, with no success. After an interval of one month each had a further three months of ampicillin, this time with probenecid, $0.5 \mathrm{~g}$. eight-hourly. Stool specimens of both patients have since been almost consistently positive. Three other patients, unable to tolerate ampicillin, were given a variety of antibiotics, including one month of cephaloridine $1 \mathrm{~g}$. twice daily intramuscularly, all without effect on their excretion of bacteria. One of these three patients became clear three months later (one year after the illness) and has remained so. Only one additional carrier was discovered-a woman who was a faecal excreter at followup examination three months after completing a three-month course of ampicillin.

\section{Discussion}

The mean inhibitory concentration of ampicillin for Salm. typhi in serum found during the Aberdeen outbreak was between 0.3 and $0.5 \mu \mathrm{g} . / \mathrm{ml}$. In the three carriers treated with ampicillin serum levels ranged from 0.96 to $1.92 \mu \mathrm{g} . / \mathrm{ml}$. at four hours when no probenecid was given, and from $15.36 \mu \mathrm{g}$./ $\mathrm{ml}$. at two hours to $0.48 \mu \mathrm{g} . / \mathrm{ml}$. at eight hours with probenecid. The action of ampicillin when effective in chronic carriers is not fully understood. It is generally believed that the bacteria in persistent infections reside intracellularly, and while ampicillin reaches a high concentration in bile, inflammatory fluid, and lymph (Brown, 1964) it shows only moderate intracellular penetration (Brumfitt, 1964). It has been suggested that the success achieved by Christie (1964) with prolonged treatment lay in the fact that, as the cells (possibly of the reticulo-endothelial system in the liver) containing bacteria die and disintegrate, the bacteria which are released are killed by ampicillin (Anderson, 1964). It is not yet known how long treatment on this basis should be continued, since the life-span of the cells which may be involved-namely, reticuloendothelial and liver cells-is uncertain. But it would appear either that more prolonged and higher dosage of ampicillin than was used in Aberdeen is required to clear bacteria from the tissues of carriers, irrespective of the serum levels at which the drug is active against Salm. typhi, or that this drug is not generally effective against the form of bacterium which persists in chronic carriers.

\section{Summary}

A double-blind clinical trial of ampicillin and inert capsules was carried out in 114 early convalescent typhoid excreters to assess the possible value of this drug in preventing the chronic carrier state. The dose of ampicillin was $4 \mathrm{~g}$. daily for adults and the duration of treatment 10 days. Twenty-three patients were withdrawn, chiefly for clinical relapse, and six others suffered clinical relapse immediately after the trial treatment period. Of the remaining 85,10 of the 45 in the ampicillintreated group and 18 of the 40 in the control group excreted Salmonella typhi afterwards, the difference being of borderline significance $(P<0.05)$. If the six clinical relapses are counted as "failures" the difference in favour of the ampicillin treatment is somewhat greater $(P<0.025)$. Further trials timed differently and in other dosages are needed before the value of ampicillin in this context is established.

Fifty-two persistent excreters completed three months' treatment with ampicillin, $3 \mathrm{~g}$. daily, and three of these excreted Salm. typhi thereafter and have become chronic carriers. Two received a further three-month course of ampicillin with probenecid, without effect. In three other persistent excreters who were intolerant of ampicillin a number of antibiotics, including cephaloridine, were unsuccessful. Although ampicillin is not always effective its use may have contributed to the low incidence in this epidemic of chronic carriers-five out of 469 confirmed cases. Its mode of action, and the possible limitations thereon, are discussed.

We are grateful for statistical advice to Professor S. J. Kilpatrick, Department of Biometry, Medical College of Virginia, formerly of the Department of Statistics, University of Aberdeen; and to Beecham Research Laboratories for a supply of ampicillin and inert capsules.

REFERENCES

Anderson, E. S., and Richards, H. G. H. (1948). F. Hyg. (Lond.), 46, 164.

Anderson, T. (1964). Practitioner, 193, 483.

Brown, D. M. (1964). Postgrad. med. Y., 40, Suppl. p. 31.

Brumfitt, W. (1964). Ibid., Suppl., p. 94.

Christie, A. B. (1964). Brit. med., f., 1, 1609.

Garbat, A. L. (1922). Monographs of the Rockefeller Institute for Medical Research, No. 16 .

Jones, A. C. (1951). F. Hyg. (Lond.), 49, 335.

Vogelsang, T. M., and Bøe, J. (1948). Ibid., 46, 252.

Walker, W. (1965). Scot. med. F., 10, 466. 